\title{
The pleural interface
}

The pleural interface is a remarkable mechanical coupling in the transmission of most of the work of breathing from the chest wall and diaphragm to the lungs. It is remarkable in that the coupling is under tension and yet there is no adhesive force between the pleurae, so that the two surfaces remain in close apposition and able to slide over each other easily with no tendency for fluid or gases in adjäcent tissues to enter the potential cavity which their separation would create. At least, this is the case under normal conditions. The basic physical and physiological principles operating in normal circumstances clearly need to be appreciated before we attempt to rationalise pathological conditions. In this article attention is focused on the forces preventing fluid and gas accumulation, the lubrication of pleural movement, and the possible role of the pleurae in energy conservation during ventilation.

The detailed morphology of the pleural cavity in relation to the bony thorax is covered. in standard texts of anatomy.' Essentially, these describe how the visceral pleura invests the lungs and interlobar surfaces while the parietal pleura is thicker and more easily separated ${ }^{2}$ from the walls of the three intrathoracic surfaces which it lines-namely, costal, mediastinal, and diaphragmatic. The physical nature of the interface will be discussed later but, histologically, each pleural surface appears as a uniform layer of flattened mesothelial cells, without a basement membrane but resting on a layer of connective tissue composed of collagen and elastic fibres.

The reason that the coupling is under tension is that the chest wall tends to recoil outwards and the lungs inwards, thus generating a negative pressure of about $5 \mathrm{~cm} \mathrm{H}_{2} \mathrm{O}$ at the interface at rest (that is, at functional residual capacity). The variation of this partial vacuum during the respiratory cycle and with age is discussed in detail in standard texts on pulmonary mechanics. ${ }^{3}$ The presence of the partial vacuum, however, raises the fundamental question of why fluid and gases dissolved in adjacent tissues do not accumulate at the interface and eventually disrupt energy transmission. This question is emphas-

Address for reprint requests: Professor Brian A Hills, Department of Anesthesiology, University of Texas Medical School, Houston, Texas 77030, USA. ised by the permeability of both pleural membranes. ${ }^{4}$

To take gases first, the reason that the pleural interface is kept gas free was first realised by Rist and Strohl, ${ }^{5}$ who pointed out that the total tension of gases dissolved in venous blood is about $73 \mathrm{~cm} \mathrm{H}_{2} \mathrm{O}$ $(54 \mathrm{~mm} \mathrm{Hg}, 7 \cdot 2 \mathrm{kPa})$ below that in arterial blood. If arterial blood is equilibrated with alveolar air, this represents a total blood-gas tension $73 \mathrm{~cm} \mathrm{H}_{2} \mathrm{O}$ below atmospheric-compared with any gas at the interface, which would have an absolute pressure only $5 \mathrm{~cm} \mathrm{H}_{2} \mathrm{O}$ below atmospheric. This gives a driving force of $68 \mathrm{~cm} \mathrm{H}_{2} \mathrm{O}$ for resolving any pneumothorax. This simple calculation, however, assumes that venous is the relevant total $\left(\mathrm{PO}_{2}+\right.$ $\mathrm{PCO}_{2}+\mathrm{PN}_{2}+\mathrm{PH}_{2} \mathrm{O}=40+46+573+47=706$ $\mathrm{mm} \mathrm{Hg}$ (or $5 \cdot 3+6 \cdot 1+76 \cdot 4+6 \cdot 3=94 \cdot 1 \mathrm{kPa})$ ), especially when one side of the pleural interface is perfused by arterial blood and the other by venous. The deficit is unlikely, however, to be less than that found in subcutaneous tissue spaces, where implanted capsules permeable to all gases develop a partial vacuum measured as $41-48 \mathrm{~mm} \mathrm{Hg}(5 \cdot 5-$ $6.4 \mathrm{kPa})$ in $\operatorname{dogs}^{6}$ and $79 \mathrm{~mm} \mathrm{Hg}(10.5 \mathrm{kPa})$ in rabbits. ${ }^{7}$ This is depicted graphically in figure 1 . The inherent unsaturation of the adjacent tissue is ample to resolve a pneumothorax, just as it provides a driving force for dissolving the bubbles produced by decompression that cause "the bends" in divers and aviators.' The same driving force applies even after a pneumothorax may have been amplified (in volume) by gaseous anaesthetics-particularly nitrous oxide. ${ }^{8}$ The physical chemistry has been described in detail elsewhere, ' but an inherent unsaturation derived from the oxyhaemoglobin dissociation curve and the relative solubilities of the metabolic gases $\left(\mathrm{O}_{2}+\mathrm{CO}_{2}\right)$ becomes a driving force for dissolving the inert gas present, which invariably becomes the rate limiting component. ${ }^{9}$ The inherent unsaturation increases in step with the oxygen partial pressure in the inspired gas $^{7}$ and this provides another reason for the recommended ${ }^{10}$ administration of oxygen in cases of pneumothorax. This leaves the question of why the negative pressure at the pleural interface does not cause the accumulation of ftuid.

Fluid shifts across the pleural interface are deter- 


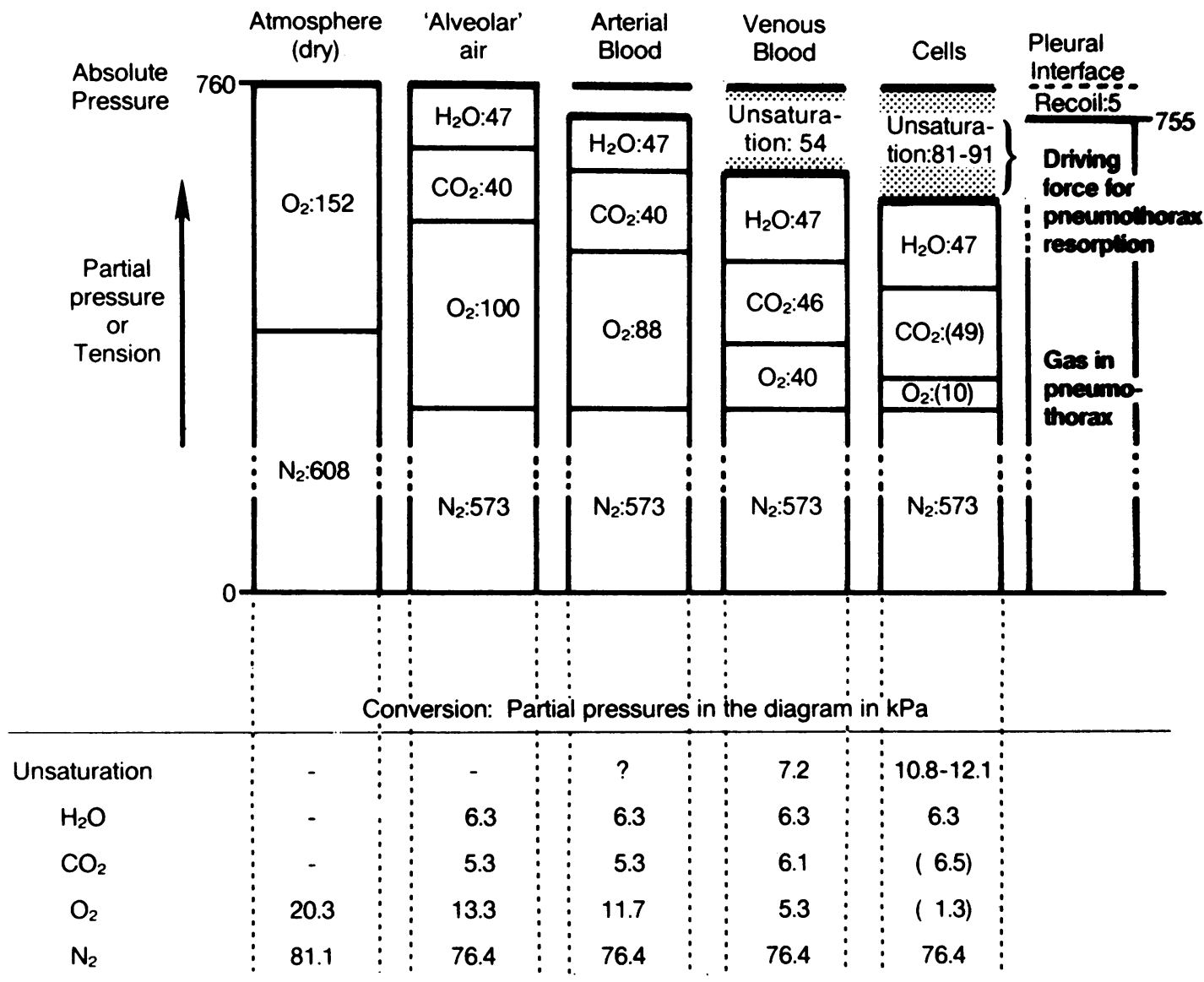

Fig 1 The gas gradients for resorption of a pneumothorax in which the gas is in the gaseous phase and the sum of the partial pressures must equal the absolute pressure (Dalton's law-which does not apply to the tensions of gases dissolved in liquid or tissue).

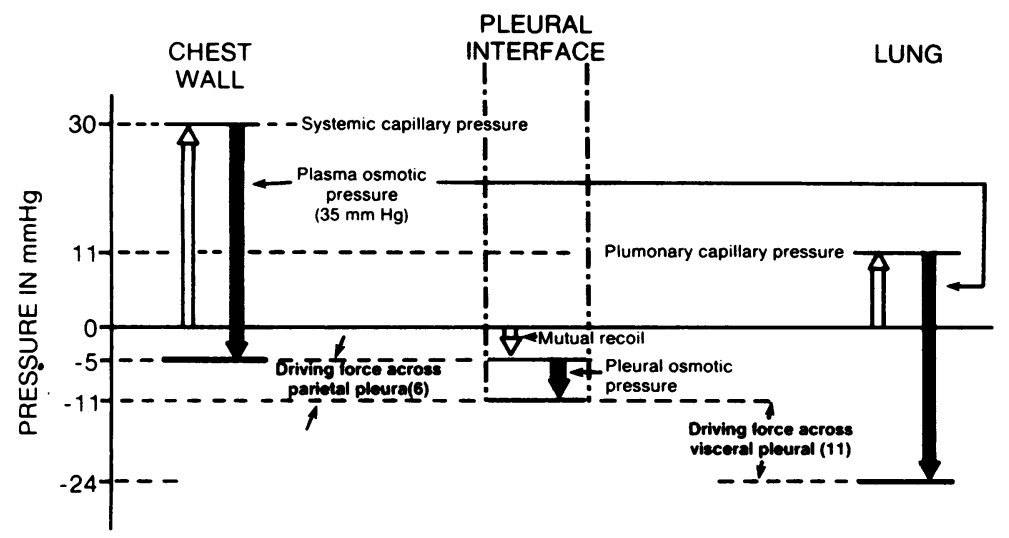

Fig 2 The hydrostatic and osmotic pressures providing the driving forces for the filtration of fuid across the parietal pleura into the interface and the resorption of that fuid by the lung. Note that the resorptive capacity of the visceral pleura will be even greater than is indicated by the comparison of driving forces owing to its greater permeability to fuid. 
mined by both hydrostatic and osmotic pressure gradients as in most other places in the body. The fact that the chest wall and diaphragm are perfused by systemic blood while the lung receives its blood from the right side of the heart is a major factor responsible for the net flux of fluid from the parietal to the visceral pleura. This does not, however, explain why fluid is prevented from accumulating at the interface, which is below venous pressure. Despite certain similarities in structure and activity, the pleurae behave quite differently with respect to resorption and permeability in general." The hydrostatic gradient from the systemic capillary bed in the chest wall $(+30 \mathrm{~mm} \mathrm{Hg})$ to the pleural interface $(-5 \mathrm{~mm} \mathrm{Hg})$ is relatively large at $35 \mathrm{~mm} \mathrm{Hg}$ but the parietal pleura is relatively impermeable, limiting the rate of filtration and producing almost protein free filtrate. At least, at about $1.5 \%$ protein $^{34}$ it could produce a colloid osmotic pressure of $8 \mathrm{~cm}$ $\mathrm{H}_{2} \mathrm{O}(6 \mathrm{~mm} \mathrm{Hg})^{3}$ or $5 \mathrm{~mm} \mathrm{Hg}{ }^{4}$ to give an osmotic gradient of $35-6=29 \mathrm{~mm} \mathrm{Hg}$ ) opposing the hydrostatic head of $35 \mathrm{~mm} \mathrm{Hg}$ for a net gradient of 6 $\mathrm{mm} \mathrm{Hg}$. At the visceral pleura the same colloid osmotic pressure of $29 \mathrm{~mm} \mathrm{Hg}$ is now tending to drive fluid into pulmonary blood-or, more likely into the lymphatics - but is opposed by a hydrostatic (venous-pleural) gradient of $11+5=16 \mathrm{~mm} \mathrm{Hg}$ to give a net driving force for resorption of $13 \mathrm{~mm} \mathrm{Hg}$. The relative pressure gradients are depicted in figure 2 . Thus the resorption capability of the visceral pleura prevails over the filtering capacity of the parietal pleura by virtue of not only the higher driving force (13 versus $6 \mathrm{~mm} \mathrm{Hg}$ ) but also the more favourable kinetics imparted by its higher permeability. Hence this imbalance provides a means of resolving a hydrothorax down to the minimum fluid volume permitted by the distension of the pleurae over areas where deeper structures such as the ribs may not allow full contact between them.

The osmotic gradients described above could be modified slightly by the ability of dissolved gases to induce osmosis in various tissues, including the lung, ${ }^{12}$ but this would be significant only with large transient gradients of inert gases likely to occur with gaseous anaesthesia or in deep sea diving. Thus fluid in a gas pocket otherwise filled with nitrous oxide would have a slightly lower driving force for resorption than one filled with nitrogen, ${ }^{13}$ but could still resolve sooner unless each gas were topped up to allow for the faster rate of disappearance of nitrogen due to its higher solubility. ${ }^{14}$

The fluid flux across the pleural interface sounds large when expressed as $20-75 \%$ per hour turnover rate of pleural fluid, ${ }^{4}$ until consideration is given to the absolute volume involved. In healthy adult males studies using thoracentesis generally. reveal less than $1.0 \mathrm{ml}$ of fluid. ${ }^{415}$ This is a very small quantity for providing lubrication unless it is particularly evenly distributed as a layer separating the moving surfaces.

Many attempts have been made to measure the interpleural pressure at different points by inserting balloons ${ }^{16}$ or by titrating the external pressure until it returns the visceral pleura to its normal configuration at sites where it has been exposed surgically. ${ }^{17}$ The results of these and other studies differ slightly but all show that the differences in pleural pressure recorded at various points are much less than the vertical head of fluid separating them. Thus the small volume of fluid is most unlikely to be present as a continuous liquid layer separating the pleurae to provide lubrication over the entire interface. Much analytical work ${ }^{18}$ has been devoted to the relationships between pleural pressure gradients, lung weight, and the configuration of the thoracic cavity but, to a first approximation, they seem to conform to the distribution which would be expected if the lung were replaced by a fluid of the same overall density. Further evidence has been produced to demonstrate the lack of continuity of the pleural fluid and the way in which the pleurae are "pulled into contact" by fluid removal ${ }^{19}{ }^{20}$ under the negative pressures described above.

The unique distribution of the negative pressure at the pleural interface provides the mechanism by which the chest wall exerts what has been aptly termed " "the shaping influence" of the thorax on the lungs. This influence considerably modifies ${ }^{22}$ the mechanics of the lung, both air and liquid filled, and hence the pressure-volume relationship for the interfacial component of lung compliance conventionally derived ${ }^{23} 24$ from the differences on a pressure basis drawn from data from excised lungs. Three quarters to seven eighths ${ }^{23}$ of the compliance of excised lungs is normally attributed to the interfacial component, derived by subtracting the pressure for liquid inflation (PL) from that for air inflation (PA) at the corresponding volume. This derivation is based on the assumption ${ }^{22} 23$ that, when liquid fills the air spaces, it eliminates a continuous liquid lining as though each alveolus were a bubble and hence eliminates the collapsing pressure of the bubble as expressed quantitatively by the Laplace equation. This bubble model is widely used to relate the role of surfactant in the lung to compliance and compliance hysteresis. ${ }^{25}$ When, however, such studies are repeated ${ }^{22}$ with the lungs within the thorax-that is, under the influence of the distribution in pleural pressure, the pressure required for inflation with liquid $(\mathrm{PL})$ is often greater than that with air (PA). Moreover, over volume ranges where $\mathrm{PA}>\mathrm{PL}$, the $d \mathrm{P} / d \mathrm{~V}$ gradient changes in the opposite direction ${ }^{22}$ 
to that predicted on the basis of surfactant acting on the surface of a bubble lining. This recent work with lungs in $\operatorname{situ}^{22}$ thus questions the very basis on which this popular bubble model ${ }^{25}$ of the alveolus was first conceived. ${ }^{23}$ The model has been challenged on other grounds in previous editorials. ${ }^{2627}$ The recent work also introduces an element of doubt into the popular use of excised lungs for studying compliance and hence the value of the data on which most of the theory of pulmonary mechanics has been derived.

Another example of how the shaping influence of the pleural pressure distribution can affect the results comes from studies designed to determine the source of the work of breathing. This has been largely attributed to the lung itself ${ }^{2425}$ because excised lungs display much compliance hysteresis, in which the pressure during inflation greatly exceeds the pressure during deflation at the same volume. Thus there is a net expenditure of work on the lung by outside forces which, in vivo, are transmitted across the pleural interface. Compliance hysteresis is traditionally attributed to two sources-that attributable to the elastic properties of the parenchymal tissue and that imparted by the interface between the alveolar surface and air. The latter is obtained by subtracting the pressures for air and liquid filled states $(P A-P L)$, as discussed above and shows a large excess of $P_{A}$ over $P_{L}$. In excised lungs both components show true hysteresis, both $P_{L}$ and $(P A-P L)$ for inflation exceeding $P_{L}$ and $\left(P_{A}-P_{L}\right)$ respectively for deflation. Thus work is done against both lung tissue elasticity and the interface during ventilation. When, however, measurements are repeated with the lungs in situ-that is, with the pleural interface intact - the tissue component $(P L)$ continues to exhibit true hysteresis but the interfacial hysteresis displays inversion, $(P A-P L)$ for deflation now exceeding $(P A-P L)$ for inflation to the same volume, at least for tidal volumes equal to FRC. ${ }^{2122}$ This is most interesting since it implies that, although there is much hysteresis in the air filled lung, this is all attributable to the parenchymal tissue, with the interfacial component actually aiding in the process of changing volume and hence in ventilation. In other words, the net compliance hysteresis of the lung is the difference between the tissue and interfacial components rather than the sum-at least, up to large tidal volumes.

This inversion of the interfacial contribution to compliance hysteresis is compatible with the similar inversion in the relationship between surface tension $(\gamma)$ and the surface area $(A)$ of films of the major pulmonary surfactant (DPL) when they are cycled to steady state. ${ }^{28}$ This applies from whichever of four directions steady state is approached, some needing several hundred cycles on the Langmuir trough.
Given the repetitive nature of respiration, this would seem much more realistic than adopting the first or third cycles quoted in conventional studies, ${ }^{25}$ in which the $\gamma: A$ hysteresis found is used to interpret the $P: V$ hysteresis found in excised lungs. Teleologically, it does not make sense for the lung to locate a surfactant at the alveolar wall, which would make the body work harder. ${ }^{26}$ Hence the inversion of both $\Delta P: V$ loops in the lungs with pleurae intact and in $\gamma: A$ hysteresis at steady state is most exciting since these findings not only are mutually consistent but imply the conversion of some other form of energy into mechanical work by the surfactant system. This arises because the surface tension for compression now exceeds that for expansion at corresponding surface areas.

The basic thermodynamic principles concerned have been described in papers on the physics of this kind of system ${ }^{28}$ but can be described qualitatively in terms of "index diagrams," which are the basis on which engineers design gas compressors, steam

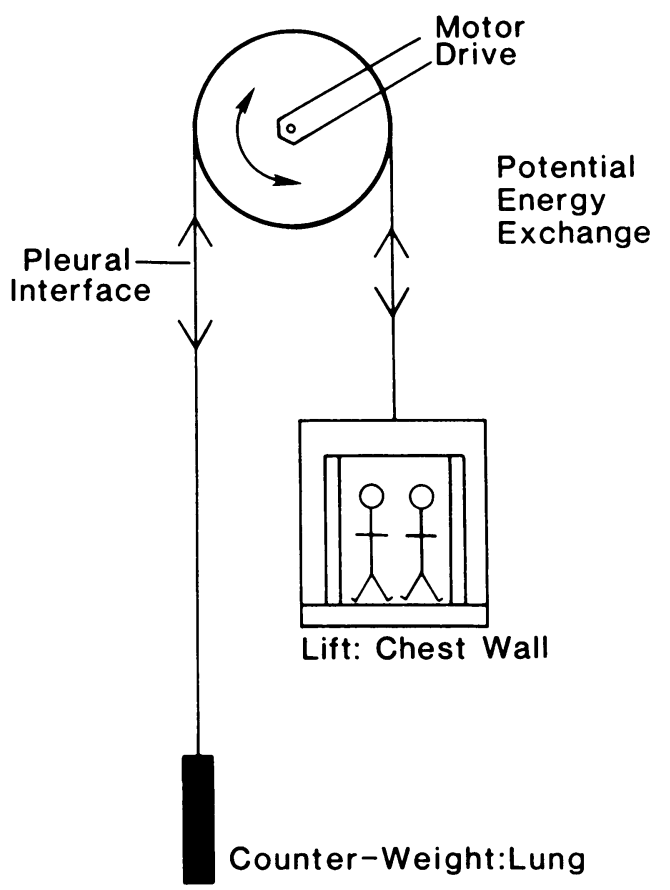

Fig 3 A cartoon depicting the pleural interface as the cable holding a lift simulating the chest wall and $a$ counterweight simulating the lungs to demonstrate the exchange of potential energy with respiration. Note that the least work is required when the weights of the lift and counterweight are equal, just as the lung needs an adequate capability to match the chest wall in storing potential energy. 
engines, etc. ${ }^{29}$ The simplest of these relates pressure to volume and displays anticlockwise $P: V$ cycles for compressors, where mechanical work is put into the system-that is, true hysteresis-while the cycles are clockwise for engines, where heat is converted into mechanical work. It is therefore most interesting to find inversion-that is, engine cycles for both $\gamma: A$ loops for surfactant cycled to steady state ${ }^{28}$ and $(P A$ $-P L): V$ (interfacial) loops for lungs in situ. ${ }^{22}$ This does not mean that the lungs are a perpetual motion machine but it does suggest that the surfactant system enables the lung to conserve some of the waste metabolic heat otherwise exhausted at the alveoli under the primary motion provided by the muscles of the chest wall and diaphragm. It can be compared to a refrigerator, where heat can be transferred from a colder to a hotter body but only under the primary motion provided by putting energy into the compressor.

The interfacial contribution to the energy needed to satisfy the work of breathing has been estimated ${ }^{28}$ to be about $23 \%$ of the total, although this figure needs to be reduced by the fraction of the alveolar surface which may be dry. ${ }^{30}$ This reduction would however, be negligible in the case of the respiratory distress syndrome (hyaline membrane disease). This is appropriately named because, if the infant dies, it does so basically because it cannot work hard enough to breathe. It is tempting to speculate that the surfactant deficiency which is known ${ }^{31}$ to be present is in part attributable to impairment of the surface engine, whose contribution would normally prevent the distress associated with the additional load placed on the muscles of the chest wall and diaphragm in the case of respiratory distress syndrome. Such considerations may also be pertinent to adult respiratory distress syndrome and the problem of weaning patients from ventilators.

When a lung is inflated a certain amount of energy is expended, some of which is lost in overcoming frictional forces while the rest is stored as potential energy by virtue of elastic distension of the structure. Much of this stored energy is associated with the alveolar surface, as we appreciate when repeating the inflation with an aqueous fluid. ${ }^{23}{ }^{24}$ This potential energy, however, is also lost on deflation if the lung is excised. On the other hand, with the pleural interface intact this energy can now be transferred to the chest wall as that structure is now distended further from its neutral position on deflation. Many standard texts ${ }^{32}$ of pulmonary physiology discuss the pressures concerned, but a major feature of the intact thoracic cavity is the ability to transfer potential energy as though the chest wall were a lift and the lung its counterweight ${ }^{26}$ with the pleurae as the connecting cable, as depicted in figure 3 . It has been pointed out how the surface tension of the alveolar lining needs to be neither too high nor too low to balance the energy storage capacity of the chest wall, just as the counterweight in this analogue needs the right value to reduce the work load on the motor to a minimum.

The pleurae need to slide on each other very easily to effect this energy exchange efficiently while imposing the shaping influence of the thorax during the complete respiratory cycle. This requires good lubrication, which until recently ${ }^{33}$ has been attributed to the fluid at the interface. ${ }^{17}{ }^{34}$ This explanation, however, would seem to conflict with the basic principles of lubrication, which can take one of three forms. The first is hydrostatic lubrication, ${ }^{35}$ which is effected by a liquid film separating the surfaces through which the fluid is injected at an adequate rate to maintain separation. The rates of filtration across the parietal pleura would seem much too low and, in any case, the greater resorbing capacity of the visceral pleura described above would make it most unlikely that a film of sufficient thickness to lubricate would be maintained over most of the interface. This argument largely eliminates the second mode of lubrication-namely, hydrodynamic lubrication, ${ }^{36}$ by which one surface planes on the wedge of fluid, thereby separating it from the counterface. The maximum velocity of sliding of the pleurae is about $5 \mathrm{~cm}$ per second, ${ }^{4}$ which would be very slow for maintaining the wedge. Hence it would seem difficult to invoke either fluid film mode of lubrication as the one facilitating sliding of the pleurae over most of their interface.

This leaves boundary lubrication, ${ }^{37}$ which operates at low velocities-even zero-and can be greatly facilitated by surfactants directly adsorbed to the surfaces of the sliding solid surfaces. The basic theory was developed in the physical sciences by Sir William Hardy ${ }^{38}$ at Cambridge at the turn of the century. Boundary lubrication applies to dry surfaces with no intervening fluid and is encountered in everyday life as the slipperiness remaining after one touches a bar of wet soap and squeezes out the water from between one's fingers. At the molecular level surfactants are good boundary lubricants and lubricant additives because, as amphiphatic molecules, the hydrophilic moieties form a reversible bond with the surface, thus orientating the hydrophobic end outwards to form a hydrocarbon surface, which slides easily over a similar hydrocarbon lining to the counterface. There are synthetic lubricants of this type, widely used industrially for many decades, in which the hydrophilic end is often a quaternary ammonium group and the hydrocarbon end is sometimes one or more fatty acid chains..$^{37}$ It would therefore seem to be no coincidence that these are the two end groups 
found on surface active phospholipids identified ${ }^{33}$ in pleural fluid. Moreover, these surfactants were found to be effective lubricants in the dry state and have therefore been proposed ${ }^{33}$ as the active agent providing lubrication for pleural sliding. When deposited as a monolayer, the principal component-dipalmitoyl lecithin (DPL)-gives a coefficient of kinetic friction of $0 \cdot 1^{33}$ which coincides with the value determined for the visceral pleura sliding against itself or against perspex. ${ }^{39}$

Boundary lubrication provided by surfactant monolayers adsorbed to the mesothelial lining would seem to provide ideal lubrication over those areas of the pleurae not separated by fluid. This concept would avoid all the objections to fluid film lubrication based on the above evidence against a continuous fluid layer at the pleural interface. It has been pointed out ${ }^{33}$ how the predominant pleural surfactant (DPL) is an ideal molecule for providing the pleural interface. The cross sectional area of the hydrophilic moiety attaching the molecule to the wall is the same $\left(40 \AA^{2}\right)$ as that of the two fatty acid chains such that close packing of one does not inhibit the other. Moreover, interspersion of calcium or other ions between the phosphate groups at the centres of the molecules is claimed ${ }^{40}$ to provide cohesion, so desirable ${ }^{37}$ in good boundary lubrication, by preventing an asperity from one surface penetrating the monolayer adsorbed to the counterface. This is interesting because phosphate is often added to lubricants to improve load bearing ability and to decrease wear ${ }^{4}$-another major factor in respiration. The ultimate interface between the pleurae is thus envisaged ${ }^{33}$ as the abutting fatty acid moieties of the two opposing monolayers of adsorbed surfactant, whose molecules when close packed with their neighbours produce a hydrocarbon surface not unlike polyethylene. This is effectively the same and has the same very slippery nature as new polythene bags. While pleural fluid can provide hydrodynamic lubrication where there are fluid pockets, these would also serve to provide replenishment of each adsorbed monolayer as they move over the surfaces during the respiratory cycle. ${ }^{33}$

This very simple method of lubrication also seems to apply to other epithelial surfaces, such as the luminal lining of the gastrointestinal tract and the pericardium (Hills BA, Butler BD, unpublished observations), where very similar surfactants with similar lubricating properties have been identified. It would appear that boundary lubrication imparted by adsorbed phospholipid might well provide a universal means of lubrication throughout the body and, almost certainly, at all visceral surfaces. This could explain the establishment of normal lubrication after pleurectomy or pericardectomy ${ }^{42}$ and normal cardiac motion in the congenital absence of the pericardium, ${ }^{43}$ where the epicardium would now slide in direct contact with the visceral and parietal pleurae. It is tempting to speculate that pleural rub ${ }^{44}$ and pericardial rub ${ }^{42}$ might be caused by a surfactant deficiency, which could be remedied by administering synthetic phospholipid.

Recent studies of synovial fluid ${ }^{40}$ have identified a mixture of essentially the same surfactants, which could provide boundary lubrication in the joints since in the dry state that mixture can give coefficients of kinetic friction as low as 0.01 -four times lower than the best man made lubricant. ${ }^{45}$ Moreover, these low values are reached under high load bearing conditions $(2.5 \mathrm{~kg} / \mathrm{cm})$ appropriate to the knee. There is therefore the possibility that a different mixture of the same surface active phospholipids may be the "active ingredient" for joint lubrication whose identification has proved so elusive. This work ${ }^{40}$ shows how effective these surfactants can be as boundary lubricants under much more severe conditions than those prevailing at the pleural interface, where the negative pressure should reduce wear. It is also tempting to speculate that, if the same biochemical pathway is followed in producing surfactant at both the pleural interface and the synovial cavity, then any deficiency in its synthesis could apply to both. This could explain the common occurrence of pleural effusion and pleurisy in patients with rheumatoid arthritis ${ }^{4}$ - whether a mechanical deficiency initiates the process or vice versa. $^{45}$ A similar situation seems to arise in the lung.

If adsorbed monolayers of surfactant effectively provide "polyethylene" linings as the ultimate surfaces which actually touch to form the pleural interface (fig 4), then they should release from each other very easily. In other words, the surfactant could act as what is often termed an "abhesive" or release agent in the physical sciences. A similar mixture of surface active phospholipids identified in the Eustachian tubes has been found to be very effective for this purpose ${ }^{46}$ in preventing tissue to tissue adhesion leading to serous otitis. ${ }^{47}$ Hence the surfactant lining to the pleurae could prevent sticking of the lung to the chest wall at zero velocity-that is, at the end of inspiration or expiration. It could also explain the remarkable ease with which the pleurae separate when air is admitted to the interface-a remarkable phenomenon given the difficulty of separating tissues or other substances as hydrophilic as the pleurae. These abhesive properties might also serve to limit the formation of "adhesions" between the pleurae after thoracic surgery, ${ }^{2}$ although this is still under investigation. 


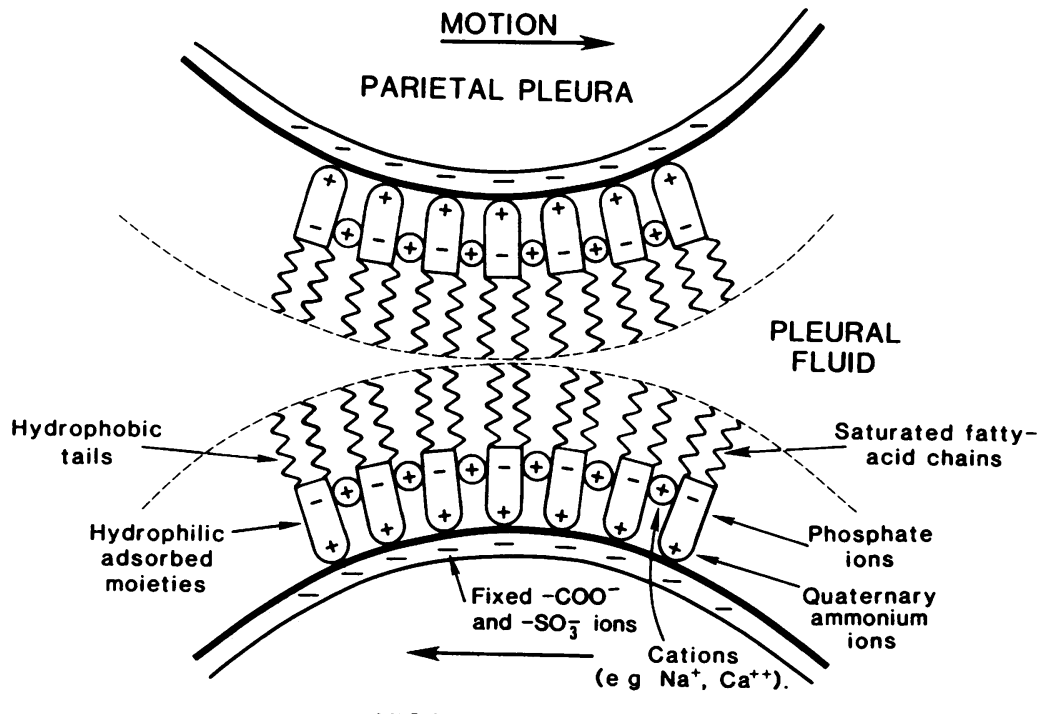

VISCERAL PLEURA

Fig 4 The concept of the pleural interface ${ }^{33} 40$ envisaged as two adsorbed monolayers of surfactant with their molecules orientated with the fatty acid chains close packed with their neighbours to provide what is effectively a polyethylene lining. This packing is enhanced by cations interspersed between the negative phosphate groups of the zwitterions to impart the cohesion that is so desirable for low wear and for good lubrication at points of high load.

In conclusion, the pleural interface appears to be a remarkably well designed system which is under tension to reduce wear but protected by gradients in gas tension and hydrostatic and osmotic pressure that prevent its uncoupling. Moreover, the ultimate interface at the molecular level would appear to be effectively two polyethylene layers that minimise wear and provide good release and lubrication even in the absence of any intervening fluid. This sytem then allows the thorax to exert its shaping influence on the lung so as to conserve energy in a manner not readily appreciated from the study of excised lungs.

BRIAN A HILLS

Department of Anesthesiology University of Texas Medical School Houston, Texas, USA

\section{References}

1 Woodburne RT. Essentials of human anatomy. 2nd ed. Oxford: Oxford University Press, 1961.

2 Takaro T. The pleura and empyema. In: Sabiston DC, ed. Textbook of surgery. Vol 2. 2nd ed. Philadelphia: Saunders, 1977:2087-98.

3 Agostoni E, Mead J. Statics of the respiratory system. In: Fenn WO, Rahn H, eds. Handbook of physiology. Vol I. Washington: American Physiological Society, 1964:387-409.

4 Black LF. Pleural effusion. In: Staub NC, Taylor AE, eds. Edema. New York: Raven, 1984:695-717.
5 Rist E, Strohl A. Sur le rôle de la diffusion dans la résorption gazeuse et le mantien de la pression sousatmosphérique dans la plévre. Presse Méd 1922;320:69-71.

6 Lategola MT. Measurement of total pressure of dissolved gases in mammalian tissue in vivo. J Appl Physiol 1964; 19:322-4.

7 Hills BA, LeMessurier DH. Unsaturation in living tissue relative to the pressure and composition of inhaled gas and its significance in decompression theory. Clin Sci 1969;36: 185-95.

8 Hunter AR. Problems of anaesthesia in artificial pneumothorax. Proc $R$ Soc Med 1955;48:765-8.

9 Van Liew H. Coupling of diffusion and perfusion in gas exit from subcutaneous pocket in rats. J Appl Physiol 1968;214: 1176-85.

10 National Oceanographic and Atmospheric Administration. The NOAA Diving Manual. Washington: United States Department of Commerce, 1975. Page 17 of Section 17.

11 Krahl VE. Anatomy of the mammalian lung. In: Fenn WO, Rahn H, eds. Handbook of physiology. Vol I. Washington: American Physiological Society, 1964;213-84.

12 Hills BA. Gas-induced osmosis in the lung. J Appl Physiol 1972;33:126-9.

13 Hills BA. Gas-induced osmosis as a factor influencing the distribution of body water. Clin Sci 1971;40:17591 .

14 Eger EI, Saidman LJ. Hazards of nitrous oxide anesthesia in bowel obstruction and pneumothorax. Anesthesiology 1965;26:61-6.

15 Yamada S. Uber die seröse Flussigkeit in der 
Pleurahöhle der gesunden Menschen. Z Ges Exp Med 1933;90:342-8.

16 Hoppin FG, Green ID, Mead J. Distribution of pleural surface pressure in dogs. J Appl Physiol 1969;27:863-73.

17 Agostoni E. Mechanics of the pleural space. Physiol Rev 1972;52:57-128.

18 Hoppin FG, Hildebrandt J. Mechanical properties of the lung. In: West JB, ed. Bioengineering aspects of the lung. New York: Dekker, 1977:83-162.

19 Agostoni E, D'Angelo E, Roncoroni G. The thickness of the pleural liquid. Respir Physiol 1968;5:1-13.

20 Agostoni E, Miserocchi G, Bonanni MV. Thickness and pressure of the pleural liquid in some mammals. Respir Physiol 1969;6:245-56.

21 Agostoni E, D' Angelo E. Thickness and pressure of the pleural liquid at various heights and with various hydrothoraces. Respir Physiol 1969;6:330-42.

22 Hills BA, Barrow RE. Discontinuous alveolar lining: air- and liquid-filled lungs inflated in situ. Fed Proc 1984; 43: 529 (abstract).

23 Von Neergaard K. Neue Auffasungen über einen Grundbegriff der Atemmechanik die Retraktionskraft der Lunge, abhängig von der Oberflächenspannung in den Alveolen. $Z$ Ges Exp Med 1929;66:373-94.

24 Radford EP. Recent studies of mechanical properties of mammalian lungs: In: Remington JW, ed. Tissue elasticity. Washington: American Physiological Society, 1957:177-90.

25 Clements JA, Tierney DF. Alveolar instability associated with altered surface tension. In: Fenn WO, Rahn H, eds. Handbook of physiology: Respiration. Vol II. Washington: American Physiological Society, 1965: 1565-83.

26 Hills BA. What is the true role of surfactant in the lung? Thorax 1981;36:1-4.

27 Hills BA. What forces keep lung air spaces dry? Thorax 1982;7:713-7.

28 Hills BA, Barrow RE. An "engine" phenomenon displayed by monolayers of a pulmonary surfactant cycled to steady state. Physics Med Biol (in press).

29 Reynolds WC. Thermodynamics. New York: McGraw-Hill, 1965:242-51.

30 Hills BA. Water repellency induced by pulmonary surfactants. J Physiol 1982;325: 175-86.

31 Avery ME, Mead J. Surface properties in relation to atelectasis and hyaline membrane disease. Am J Dis Child 1959;97:517-23.

32 Otis AB. The work of breathing. In: Fenn WO, Rahn H, eds. Handbook of physiology: Respiration. Vol I. Washington: American Physiological Society,
1965:469.

33 Hills BA, Butler BD, Barrow RE. Boundary lubrication imparted by pleural surfactants and their identification.J Appl Physiol: Respir Environ Exercise Physiol 1982;53:463-9.

34 Rohrer F. Physiologie der Atembewegung. In: Ellinger A, ed. Handbuck der Normalen and Pathologischen Physiologie. Vol II. Berlin: Springer, 1925:70-127.

35 Fuller D. Hydrostatic lubrication. In: O'Connor JJ, Boyd J, Avallone EA, eds. Standard handbook of lubrication engineering. New York: McGraw-Hill, 1968:3.17-20.

36 Boyd J, Raimondi AA. Hydrodynamic lubrication: fundamental requirements. In: O'Connor JJ, Boyd J, Avallone EA, eds. Standard handbook of lubrication engineering. New York: McGraw-Hill, 1968:3.1-16.

37 Godfrey D. Boundary lubrication. In: O'Connor JJ, Boyd J, Avallone EA, eds. Standard textbook of lubrication engineering. Ch 2. New York: McGraw-Hill, 1968.

38 Hardy WB. Collected papers of Sir William Hardy. Cambridge: Cambridge University Press, 1936.

39 Brandi G. Determinazione del coefficiente di attrito statico tra le due pleure. Boll Soc Ital Biol Sper 1970; 46:427-29.

40 Hills BA, Butler BD. Surfactants identified in synovial fluid and their ability to act as boundary lubricants. Ann Rheum Dis 1983;43:641-8.

41 Larson CM, Larson $R$. Lubricant additives. In: O'Connor JJ, Boyd J, eds. Standard handbook of lubrication engineering. Ch 14. New York: McGraw-Hill, 1968.

42 Winters WL jun, Cortes FM. Pericardial disease. In: Conn HL, Horwitz O, eds. Cardiac and vascular diseases. Vol II. Philadelphia: Lea and Febiger, 1971:1326-64.

43 Hering CA, Wilson SJ, Ball ER. Congenital deficiency of the pericardium. J Thorac Cardiovasc Surg 1960;40:49-55.

44 Cherniak RM, Cherniak L, Naimark A. Respiration in health and disease. 2nd ed. Philadelphia: Saunders, 1972:250-1.

45 McCutchen CW. Lubrication of joints. In: Sokoloff M, ed. The joints and synovial fuid. Vol I. New York: Academic Press, 1978:438-83.

46 Hills BA. Analysis of Eustachian surfactant and its function as a release agent. Arch Otol 1984;110:3-9.

47 Birken EA, Brookler KH. Surface tension lowering substance of the Eustachian tube in non-suppurative otitis media: an experiment with dogs. Laryngology 1973;83:255-8. 